\title{
COMPARISON OF LIDAR-BASED MODELS FOR TRUE LEAF AREA INDEX AND EFFECTIVE LEAF AREA INDEX ESTIMATION IN YOUNG BEECH FORESTS
}

\author{
Zdeněk Patočka ${ }^{1}$ Kateřina Novosadová², Pavel Haninec ${ }^{3}$, Radek Pokorný², \\ Tomáš Mikitaํㅜ Martin Klimánek ${ }^{1}$ \\ ${ }^{1}$ Department of Forest Management and Applied Geoinformatics, Faculty of Forestry and Wood Technology, \\ Mendel University in Brno, Zemědělská 1, 61300 Brno, Czech Republic \\ ${ }^{2}$ Department of Silviculture, Faculty of Forestry and Wood Technology, Mendel University in Brno, Zemědělská 1, \\ 61300 Brno, Czech Republic \\ ${ }^{3}$ Department of Forest Botany, Dendrology and Geobiocoenology, Faculty of Forestry and Wood Technology, \\ Mendel University in Brno, Zemědělská 1, 61300 Brno, Czech Republic
}

Link to this article: https://doi.org/10.11118/actaun202068030559

Received: 9. 3. 2020, Accepted: 31. 5. 2020

To cite this article: PATOČKA ZDENĚK, NOVOSADOVÁ KATEŘINA, HANINEC PAVEL, POKORNÝ RADEK, MIKITA TOMÁŠ, KLIMÁNEK MARTIN. 2020. Comparison of LiDAR-based Models for True Leaf Area Index and Effective Leaf Area Index Estimation in Young Beech Forests. Acta Universitatis Agriculturae et Silviculturae Mendelianae Brunensis, 68(3): 559-566.

\begin{abstract}
The leaf area index (LAI) is one of the most common leaf area and canopy structure quantifiers. Direct LAI measurement and determination of canopy characteristics in larger areas is unrealistic due to the large number of measurements required to create the distribution model. This study compares the regression models for the ALS-based calculation of LAI, where the effective leaf area index (eLAI) determined by optical methods and the LAI determined by the direct destructive method and developed by allometric equations were used as response variables. LiDAR metrics and the laser penetration index (LPI) were used as predictor variables. The regression models of LPI and eLAI dependency and the LiDAR metrics and eLAI dependency showed coefficients of determination $\left(\mathrm{R}^{2}\right)$ of 0.75 and 0.92, respectively; the advantage of using LiDAR metrics for more accurate modelling is demonstrated. The model for true LAI estimation reached a $\mathrm{R}^{2}$ of 0.88 .
\end{abstract}

Keywords: airborne laser scanning, LiDAR, leaf area index, effective leaf area index, LAI, eLAI, allometric models, destructive method, indirect methods

\section{INTRODUCTION}

The most used environmental indicator characterizing the canopy structure is leaf area index (LAI). LAI is a key feature of the forest structure that serves as the primary indicator for the exchange of matter and energy within forest ecosystems. LAI is a dimensionless variable characterized as the maximum area of photosynthetic tissue per unit of ground area (Myneni et al., 1997). The amount of LAI depends on the species composition of the stand, the development stage, the prevailing site factors, the season, and the type of forest management. It is a dynamic parameter that changes from day to day (especially in spring and autumn), and over time, the physical and biological forces that form and change the forest environment affect it. LAI is likewise one way to evaluate the health status of trees unfolding from these factors. Methods for LAI detection can be divided into three categories: direct, semidirect, and indirect. The direct methods generally use destructive procedures to estimate the total number of leaves on the tree and their areas, whereas the indirect methods use some 
aspect of the radiation regime within the stand and derive LAI from light distribution under the canopy (Jonckheere et al., 2004).

The direct methods are most accurate for sample trees but very time-consuming; therefore, they are not used for the determination of spatial and temporal LAI distribution. However, they may be considered the most important for validation of indirect methods. These include the destructive method of collecting leaves from standing trees and collecting falling leaves to litter-traps (Jonckheere et al., 2004). The direct destructive method damages trees irreversibly, so it is not used in larger and more valuable trees. The semi-direct methods include allometric models based on simple physical dimensions (diameter at breast height (DBH), tree height, base crown, crown projection, etc.) as predictor variables and LAI as a response variable determined by the direct method (Asner et al., 2003). Allometric relations are accurate, but they are stand-specific or species-specific (Mencuccini and Grace, 1995; Le Dantec et al., 2000).

Currently, indirect methods based on non-contact transmittance measurements are used in forest stands. These methods use the Beer-Lambert law (Monsi and Saeki, 2005).

The leaf area index can be determined on the basis of gap fraction information or based on the combination of gap fraction and gap size distribution using tracing radiation and architecture of canopies (TRAC) or hemispheric photo analysis (Chen and Cihlar, 1995).

The indirect optical methods are characterized by nonseparation of the leaves from different parts of the crown layer, such as branches or parts of the stem. The indirect methods determine so-called effective leaf area index (eLAI), which can be used for recalculation into true LAI by the correction factor, which is stand-specific and species-specific. The factor reflects the mutual overlapping of the needles within the annual shoot, the branches, and the whorls, thus the proportion of wood in the sensor field of view (Chen et al., 1991). In the case of beech, this factor is not used, because leaves are mostly randomly distributed. Therefore, to determine true LAI, it is sufficient to repeat the measurement out of the vegetation period; the woody area index (WAI) is determined and subtracted from eLAI (Caldwell et al., 1983a; 1983b).

The indirect techniques using remote sensing are the most suitable for estimating LAI on a wider spatial scale. We can divide them into techniques using passive optical sensors and LiDAR. The basis of LAI estimation using passive optical sensors is the correlation between LAI and some of the vegetation indices, e.g., Normalized Difference Vegetation Index (NDVI) (Lüdeke et al., 1991; Gower et al., 1999). The disadvantage is seen especially in case of high LAI value occurrences when the NDVI is so saturated that it is unable to distinguish these high LAI values, which means the NDVI and LAI will not increase linearly (Zheng and Moskal, 1991). The other technology is airborne laser scanning (ALS), which has been used in most studies to estimate an effective leaf index, but is not correct in case of non-random distribution of foliage and does not distinguish nonfoliage elements (e.g., branches, bark) in the canopy. Corrections must be made for calculation of true LAI (Chen et al., 1997; Leblanc et al., 2005).

Airborne laser scanning uses a laser scanner carried mainly by satellite, aircraft, helicopter or unmanned aerial vehicle. The entire system is able to capture accurate three-dimensional data thanks to the inertial navigation system (INS) and Global Navigation Satellite System. Most studies have used small-footprint, discrete return scanners, and LAI estimation using some penetration indices (semiempirical approach) or LiDAR metrics (empirical approach). The created models are valid only for the trees and stands for which they were derived and calibrated (Riaño et al., 2004; Solberg et al., 2010). ALS-based models for eLAI estimation can be calibrated using terrestrial laser scanning (Musselman et al., 2013).

In this paper, we compare different regression models based on the laser penetration index and LiDAR metrics as predictor variables and models based on effective leaf area index and true leaf area index as response variables. We focused only on modelling of young beech forest stands, because in situ measurements, especially by the direct destructive method, are time-consuming. There are not many studies using true LAI as the response variable in ALS-based modelling, e.g., (Beets et al., 2011; Qu et al., 2018). eLAI as response variable is commonly used for LAI estimation based on remote sensing resulting in underestimation of true LAI.

\section{MATERIALS AND METHODS}

\section{Study Area}

The field measurements were carried out during August and September 2015 at the University Forest Enterprise Krrtiny (UFE), an organizational part of Mendel University in Brno, Czech Republic. The sample plots were placed in young beech forest stands (21 years old) with a tree species composition of 91\% beech (Fagus sylvatica L.), 8\% larch (Larix decidua Mill.), and 1\% oak (Quercus petraea Matt.). The average tree height of the forest stand was $9 \mathrm{~m}$ and the average $\mathrm{DBH}$ was $9 \mathrm{~cm}$. In total, 6 sample plots were surveyed tacheometrically using total station.

\section{ALS Data Acquisition and Initial Processing}

The airborne laser scanning data used in this study was scanned on September 17 and 18, 2014, in the ETRS-89 UTM 33N coordinate system and the GRS-80 geodetic reference system. The parameters of airborne laser scanning acquisition are shown in Tab. I. 
I: Area laser scanning (ALS) acquisition parameters

\begin{tabular}{lc}
\hline \multicolumn{1}{c}{ Sensor } & Leica ALS70 \\
\hline Date & Sept. 2014 \\
Flight speed $\left(\mathrm{ms}^{-1}\right)$ & 70 \\
Flying altitude (m a.g.l.) & 700 \\
Pulse repetition frequency (kHz) & 301.8 \\
Pulse density & 7.8 \\
Half scan angle (deg.) & 24 \\
\hline
\end{tabular}

The data classification was performed in TerraScan software. Ground points were classified by automatic methods as Class 2, Ground, and first return points as Class 5, High Vegetation.

\section{Destructive Methods and Allometric Equations}

All tree girths at breast height were measured in the forest stands, and 9 sample trees were chosen on the basis of the girth distribution frequency. Each sample tree was cut into $1 \mathrm{~m}$ sections, from which sample leaves were collected for calculation of SLA, and then LAI.

The sample leaves were scanned immediately after harvesting, and their exact area was determined using Image image analysis software (National Institutes of Health, Bethesda, MD, USA). These leaves were dried for $48 \mathrm{~h}$ at $105^{\circ} \mathrm{C}$ and then weighed with milligram precision. The specific leaf area of the leaves was calculated from the known dry mass by the following formula:

$S L A=S_{f} \times m_{d}^{-1}$,

where:

$S_{f} \ldots . . . . .1$ leaf fresh mass area and

$m_{d}$.....dry mass weight.

All leaves of individual sections were also harvested and dried for $48 \mathrm{~h}$ at $105^{\circ} \mathrm{C}$. After being weighed, the ratio of SLA to tree segment was applied and the segment leaf area was calculated. Based on a regression analysis, allometric equations were created where tree girth was used as an independent variable. Leaf areas on the plots were estimated based on these dependencies.

\section{Indirect Methods}

LAI-2200 Plant Canopy Analyzer (Li-cor Inc.), hemispherical photographs, and PSI LaiPen LP 100 (Photon Systems Instruments, s. r. o.) were used to measure effective leaf area. The use of these tools requires the absence of direct sunlight; thus, all measurements were performed strictly in diffuse radiation (homogeneously overcast sky or short time before sunrise or short time after sunset).

Two sensors of the LI-COR LAI-2200 PCA were used to determine LAI. One sensor was set up on a tripod at a height of $180 \mathrm{~cm}$ in an unshaded area, where it was set to automatically measure radiation at half-minute intervals. eLAI was determined based on comparing radiation in the forest stand and in the area with a clear view of the sky.

The LaiPen LP 100 works on a similar principle as the LI-COR LAI 2200 PCA. The instrument measures the transmittance value as the irradiance ratio obtained under and over the canopy. Two instruments were used, one on a reference area with a clear view of the sky and the other to measure in the plots. Horizontal levelling of the instrument was achieved using the gyroscope integrated within it.

Effective leaf index was also determined by image analysis of hemispherical photographs. For this purpose, a set consisting of a Sony NEX-7 camera with an FC-E8 fish-eye lens served to capture images with a field of view of $180^{\circ}$. The entire system was installed into the auto-levelling platform to keep the camera in the horizontal position. Effective leaf area index was estimated in WinScanopy software (Regent Instruments Inc.).

\section{LAI Estimation Using ALS Data}

In ArcMap (ESRI Inc.) software, the laser penetration index for each sample plot $5.5 \mathrm{~m}$ in diameter was calculated by using the following formula (Musselman et al., 2013):

$L P I=\frac{m G}{m G+m V}$

where:

$m_{G}$....the number of returns belonging to the ground per unit area and

$m_{V} \ldots . .$. the number of first returns per unit area.

The area size for the LPI calculation was determined by correlation matrices. LPI was calculated for different area sizes, and the highest correlation with the eLAI measurement results was sought. Area size depends on instrument field of view and tree heights (or crown projection for the destructive method) (Mikita et al., 2011). The size of the plots cut out from the point cloud has a significant effect on the success of regression models.

Another method of LAI calculation by laser scanning was the use of LiDAR metrics, which were calculated in FUSION software (US Department of Agriculture, Forest Service, Pacific Northwest Research Station). In the beginning, the sample plots (square shape, diameter $5.5 \mathrm{~m}$ ) were clipped from the point cloud by the clipdata command, then the LiDAR metrics of the individual plots were calculated using the cloudmetrics command. The cloudmetrics command computes a variety of metrics describing a point cloud. This metrics are based on point elevation attributes and return intensity (for more details, see the FUSION manual (McGaughey et al., 2018)). Most significant metrics are percentile values for point elevations and various ratios of returns above specific height 
breaks. The LiDAR metrics were selected using the sequential replacement technique in the leaps package for $R$. These selected metrics served as predictors for the linear regression model. A regression triplet was tested in the final models.

\section{RESULTS}

\section{Linear Regression Model Based on LPI (Predictor) and eLAI (Response)}

Using the $P M C M R$ package for $R$, the Friedman test and the Neményi test of multiple comparison was used. Optical methods were found to provide similar results (Tab. II, Fig. 1).

Therefore, a mean of eLAI values per sample plot measured by the LI-COR LAI-2200 PLA were used as response variables. An important part of the regression analysis is examination of the regression triplet, i.e., procedures for identifying the model quality for a given set of data, the data quality of a proposed model, and fulfilment of all least-squares assumptions. The following tests were performed: Fisher-Snedecor overall test, Scott's multicollinearity criterion, Cook-Weisberg test for heteroscedasticity, Jarque-Berra test for normality, Wald test for autocorrelation, Durbin-Watson test for autocorrelation, and sign test. Based on these tests, no negative conclusions that would affect the credibility of the regression model were drawn. The resulting linear regression model is described in Tabs. III and IV. Tab. IV shows the estimates and significances of regression model parameters. All parameters are significant.

II: Friedman and Neményi post-hoc test. The significant differences are highlighted in bold.

\begin{tabular}{lccc}
\hline & \multicolumn{4}{c}{ Friedman Chi-Squared } & $=230.57, d f=3, p$-value $<2.2 * 10^{-16}$ \\
\hline Fi-COR & Fish-eye & Li-COR & LaiPen \\
LaiPen & 0.98 & - & - \\
Direct & 0.97 & 1.00 & - \\
\hline
\end{tabular}

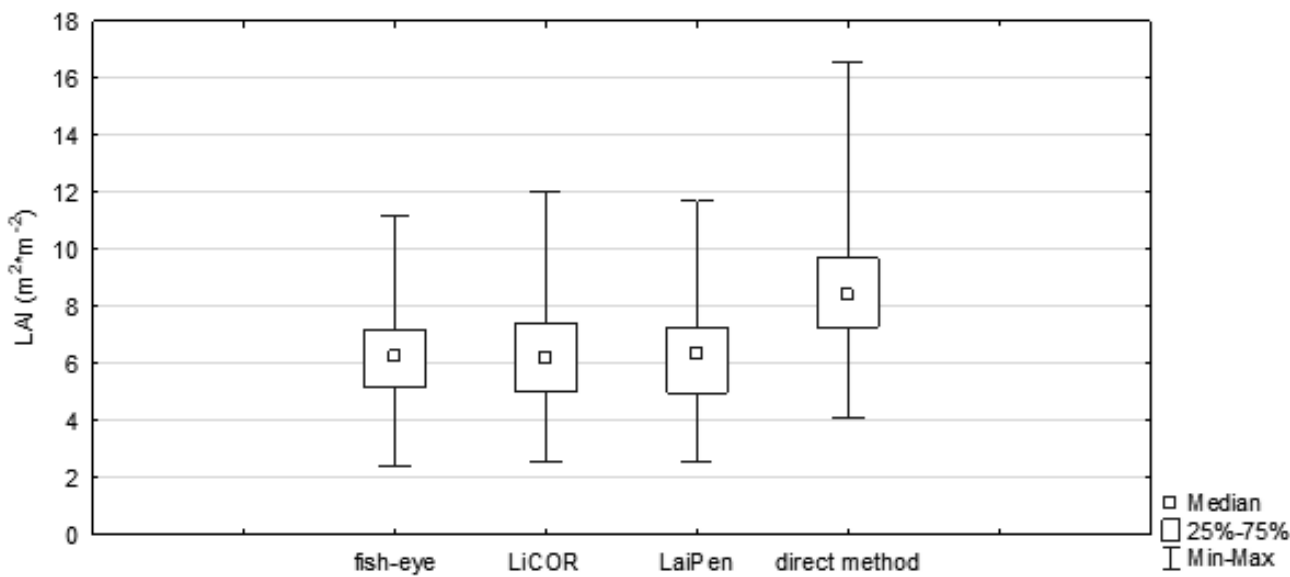

1: Box plot of LAI values determined by individual methods

III: Statistical characteristics of regression model based on LPI and eLAI

\begin{tabular}{lc}
\hline \multicolumn{1}{c}{ Coefficient of Determination $R^{2}$} & 0.7450 \\
\hline Mean squared prediction error (MSPE) & 1.4426 \\
Akaike information criterion $(A I C)$ & -0.1598 \\
Cross-validated $R^{2}$ & 0.398 \\
Cross-validated $R M S E$ & 1.2 \\
\hline
\end{tabular}

IV: Estimation of regression model parameters

\begin{tabular}{lcccccc}
\hline & Variable & Estimate & Std. Error & Conclusion & p-Value & Lower Limit Upper Limit \\
\hline Intercept & 10.6855 & 1.3520 & Significant & 0.0014 & 6.9317 & 14.4393 \\
LPI & -29.0258 & 8.4901 & Significant & 0.0268 & -52.5981 & -5.4535 \\
\hline
\end{tabular}


V: Statistical characteristics of regression model based on LiDAR metric and eLAI

\begin{tabular}{lc}
\hline \multicolumn{1}{c}{ Coefficient of Determination $R^{2}$} & 0.9212 \\
\hline Mean squared prediction error $(M S P E)$ & 0.4189 \\
Akaike information criterion $(A I C)$ & -7.209 \\
Cross-validated $R^{2}$ & 0.791 \\
Cross-validated $R M S E$ & 0.65 \\
\hline
\end{tabular}

VI: Estimation of regression model parameters

\begin{tabular}{lcccccc}
\hline \multicolumn{1}{c}{ Variable } & Estimate & Std. Error & Conclusion & p-value & Lower Limit Upper Limit \\
\hline Abs & -8.2859 & 2.1303 & Significant & 0.0177 & -14.2007 & -2.3713 \\
Percentage of all returns above 2.00 & 0.2073 & 0.0303 & Significant & 0.0024 & 0.1232 & 0.2915 \\
\hline
\end{tabular}

VII: Allometric model parameters and statistical characteristics

\begin{tabular}{ccccc}
\hline Formula & $a$ & $R^{2}$ & MSPE & AIC \\
\hline $\mathrm{y}=\mathrm{e}^{\mathrm{ax}}$ & 0.0893 & 0.83 & 81.62 & 32.29 \\
\hline
\end{tabular}

VIII: Statistical parameters of the resulting regression model for LAI estimation based on LiDAR metrics

\begin{tabular}{cccccccc}
\hline Parameter & Predictor & $R^{2}$ & $R M S E$ & AIC & $c \nu R^{2}$ & cvRMSE & Indirect Method Correlation \\
\hline \multirow{2}{*}{0.1984} & $\begin{array}{c}\text { Percentage of all } \\
\text { returns above mean }\end{array}$ & 0.8665 & 0.4758 & -4.6020 & 0.875 & 0.69 & 0.51 \\
\hline
\end{tabular}

Another model uses the most correlated LiDAR metric as a predictor. Based on these tests, no negative conclusions that would affect the credibility of the regression model were drawn. The resulting linear regression model is described in Tabs. V and VI. Tab. VI shows the estimates and significances of the regression model parameters. All parameters are significant.

\section{Allometric Equations for LAI Determination at Plot Level}

Several allometric models (tree girth as predictor and leaf area as response) using nonlinear regression analysis (power, exponential, and polynomial functions) were created on the basis of girths and leaf areas of nine sample trees, where girth is predictor variable and leaf area is response variable. The Gauss-Newton derivative method of numerical nonlinear optimization was used for model fitting in most of the cases. In case of method divergence, derivative-free method simplex was used. Most models contain errors in the regression triplet. The power and polynomial model contain a residual dependency. The exponential model in the form $\mathrm{y}=\mathrm{ae}^{\mathrm{bx}}$ contains heteroscedasticity and residual dependency; therefore, the model was refitted to the form $y=e^{a x}$. The regression triplet test of the second exponential model showed no negative conclusions that would affect the credibility of the regression model. Allometric model parameters and statistical characteristics are described in Tab. VII.

\section{LAI Modelling-Based LiDAR Metrics (Predictors)}

LAI was determined on plots by using the abovementioned allometric equations. Linear regression model-based LiDAR metrics for LAI estimation were fitted. The best predictors were selected using sequential replacement techniques in the leaps package for $\mathrm{R}$. These models were validated using leave-one-out cross-validation (LOOCV). Tab. VIII shows the parameter estimate and predictor variable for regression model, including statistical parameters and results of cross-validation and correlation with indirect method.

\section{DISCUSSION}

The range of LAI values depends on the method of estimation used. The eLAI values detected by the optical methods were similar and the differences between them were statistically insignificant. Based on analysis of variance, we can say that the optical methods (more precisely, the devices used) underestimated the true leaf area; LAI determined by the direct destructive method was more accurate by $29 \%$, on average.

Bréda (2013) compared the LAI values measured using the LI-COR LAI 2000 PCA instrument with measurement by litter-traps. The LAI values of other plots of our study are higher (max. $11.80 \mathrm{~m}^{2} \cdot \mathrm{m}^{-2}$ ), because Bréda (2013) used another direct method, determination by litter-traps. Morrison (1991) reported a bias of $10 \%$ with respect to the average. 
The results of Bréda (2013) obtained by LAI 2000 PCA ranged from 4.2 up to $5.2 \mathrm{~m}^{2} . \mathrm{m}^{-2}$, similar to our results. The deviation of direct and indirect methods is also similar.

Mussche et al. (2001) determined eLAI (LAI) values by LAI 2200 PCA, hemispherical photos, and littertraps ranging from 3.68 to $5.08 \mathrm{~m}^{2} \cdot \mathrm{m}^{-2}$ for stands with 50\% beech composition; the highest values were reached by the litter-traps. In comparison with LAI directly measured by litter-trap, the underestimation of LAI calculated by hemispheric photo analysis was $27.55 \%$ and by the LAI 2200 PCA was $21.65 \%$. The underestimation is comparable to our study despite the different approach to the direct method. The average underestimation of the LAI 2200 PCA in comparison with litter-traps was determined by Cutini et al. (1998) to be $29.57 \%$, and that again corresponds to our study despite the use of the different direct method.

In case of LiDAR utilization for LAI modelling, it very much depends on the method of obtaining a response variable, whether it is eLAI computed by optical methods or LAI obtained by direct measurement. Airborne laser scanning generally correlates well with hemispherical photos, which can be extended to all optical methods (Alonzo et al., 2015). ALS is a suitable. technology for aerial mapping of LAI distribution, and this is confirmed by many earlier studies, e.g., (Riaño et al., 2004; Solberg, 2010; Musselman et al., 2013; Alonzo et al., 2015; Kwak et al., 2007; Barilotti et al., 2006; Peduzzi et al., 2012; Pirotti, 2011).

Several regression models were created with coefficients of determination ranging from 0.75 to 0.92, whereas models containing LiDAR metrics as predictor variables achieved higher coefficients. It was not possible to create an LPI model to estimate
LAI with the destructive method as response variable. The higher success using LiDAR metrics is mainly due to preservation of the total amount of points in the point cloud; in the case of LPI, the first return points and points on the ground were used. Therefore, LiDAR metrics had better describe the vertical structure of the stand. Kwak et al. (2007) made similar claims; they reached higher coefficients of determination than in the case of LPI by using the Laser Interception Index (LII), which they explain by preservation of the total amount of points.

Riaño et al. (2004) stated that LAI estimation is generally better for deciduous than coniferous stands. Barilotti et al. (2006) created a regression model for eLAI calculation with a $R^{2}$ of 0.89 ; field measurements were carried out using the LI-COR LAI-2000 PCA. Musselman et al. (2013) created a regression model with a $R^{2}$ of 0.64 ; they performed 24 measurements using hemispherical photo analysis. Kwak et al. (2007) created equations of eLAI and LPI dependence for three tree species. They reached $R^{2}$ of 0.73 for Larix leptolepis Sieb. et Zucc. and $R^{2}$ of 0.81 for Quercus spp. and Pinus koraiensis Sieb. et Zucc. They also used a different index than the LPI (the laser interception index), thus they achieved higher coefficients of determination (0.85-0.88). Peduzzi et al. (2012) created a regression model for mixed forests in Virginia, which explained 69\% variability of eLAI. In combination with radar interferometry data, they created a model with a $R^{2}$ of 0.77 . Solberg (2010) estimated eLAI from ALS data in pine stands affected by defoliation; the created models had very high coefficients of determination (from 0.92 to 0.94). Higher coefficients of determination may be related to a smaller overlay of the leaves and better laser beam penetration.

\section{CONCLUSION}

The created models are valid only at the regional level or at the level of the forest-like structure, i.e., stands with similar species composition and age. Pirotti (2011) mentioned the same; the regression models published here are similar to the regression rebate as models of other authors. Most authors developed ALS-based models for calculation of effective LAI. However, the destruction methods are the most accurate. This work has revealed a significant benefit of using LiDAR metrics compared to the laser penetration index, also for modelling of effective leaf area index. Qu et al. (2018) confirm it, but they recommend using the height metrics. In our research, the density metric Percentage of all returns above mean was used. In the empirical approach to modelling, both height and density metrics are calculated, and the best ones are selected. Qu et al. (2018) also points out the risk of multicollinearity between similar height metrics. Using height and density metrics together will avoid multicollinearity.

However, an effective LAI usually underestimates the actual LAI. This paper of showed the possibilities of upscaling the actual LAI using airborne laser scanning. The LiDAR metrics-based model reach the $R^{2}$ of 0.87 , the highest coefficient of determination during the cross-validation (0.88), and the lowest cross validated root mean square error (0.69).

\section{Acknowledgements}

This work was supported by the Internal Grant Agency of Faculty of Forestry and Wood Technology, Mendel University in Brno. The paper was worked out as a part of research project reg. No. LDF VP_2016015, "Use of point clouds derived by unmanned aerial vehicle imagery and airborne laser 
scanning for leaf area index estimation”. The paper publishing was also financed by the National Agency of Agricultural Research in the Czech Republic, research project reg. No. QK1810415, "Influence of forest stands species composition and structure on the microclimate and landscape hydrology".

\section{REFERENCES}

ALONZO, M., BOOKHAGEN, B., MCFADDEN, J. P. et al. 2015. Mapping urban forest leaf area index with airborne lidar using penetration metrics and allometry. Remote Sensing of Environment, 162: 141-153.

ASNER, G. P., SCURLOCK, J. M. O. and HICKE, J. A. 2003. Global Synthesis of Leaf Area Index Observations: Implications for Ecological and Remote Sensing Studies. Global Ecology \& Biogeography, 12(3): 191-205.

BARILOTTI, A., TURCO, S. and ALBERTI, G. 2006. LAI determination in forestry ecosystem by lidar data analysis. In: International workshop 3D remote sensing in forestry. Wien: BOKU, pp. 248-252.

BEETS, P. N., REUTEBUCH, S., KIMBERLEY, M. O. et al. 2011. Leaf Area Index, Biomass Carbon and Growth Rate of Radiata Pine Genetic Types and Relationships with LiDAR. Forests, 2(4): 637-659.

BRÉDA, N. J. J. 2003. Ground-based measurements of leaf area index: a review of methods, instruments and current controversies. Journal of Experimental Botany, 54(392): 2403-2417.

CALDWELL, M. M., DEAN, T. J., NOWAK, R. S. et al. 1983a. Bunchgrass architecture, light interception and water-use efficiency: Assesment by fiber optic point quadrants and gas exchange. Oecologia, 59(2-3): 178-184.

CALDWELL, M. M., HARRIS, G. W. and DZUREC, R. S. 1983b. A fiber optic point quadrant system for improved accuracy in vegetation sampling. Oecologia, 59: 417-418.

CHEN, J. M., BLACK, T. A. and ADAMS, R. S. 1991. Evaluation of hemispherical photography for determining plant area index and geometry of a forest stand. Agricultural and Forest Meteorology, 56(1): 129-143.

CHEN, J. M. and CIHLAR, J. 1995. Plant canopy gap size analysis theory for improving optical measurements of leaf area index. Applied Optics, 34(27): 6211-6222.

CHEN, J. M., RICH, P. M., GOWER, S. T. et al. 1997. Leaf area index of boreal forests: theory, techniques, and measurements. Journal of Geophysical Research-Atmospheres, 102(D24): 29429-29443.

CUTINI, A., MATTEUCCI, G. and MUGNOZZA, G. S. 1998. Estimation of leaf area index with the Li-Cor LAI-2000 in deciduous forests. Forest Ecology and Management, 105(1-3): 55-65.

GOWER, S. T., KUCHARIK, C. J. and NORMAN, J. M. 1999. Direct and indirect estimation of leaf area index, fAPAR, and net primary production of terrestrial ecosystems. Remote Sensing of Environment, 70(1): 29-51.

JONCKHEERE, I., FLECK, S., NACKAERTS, K. et al. 2004. Review of methods for in situ leaf area index determination. Part I. Theories, sensors and hemispherical photography. Agricultural and Forest Meteorology, 121(1): 19-35.

KWAK, D. A., LEE, W. K. and CHO, H. K. 2007. Estimation of LAI using LiDAR remote sensing in forest. In: RÖNNHOLM, P. et al. (Eds.). Proceedings of the ISPRS Workshop on Laser Scanning and SilviLaser. Espoo-Finland.

LE DANTEC, V., DUFRENE, E. and SAUGIER, B. 2000. Interannual and spatial variation in maximum leaf area index of temperate deciduous stands. Forest Ecology and Management, 134(1/3): 71-81.

LEBLANC, S. G., CHEN, J. M., FERNANDES, R. et al. 2005. Methodology comparison for canopy structure parameters extraction from digital hemispherical photography in boreal forests. Agricultural and Forest Meteorology, 129(3-4): 187-207.

LÜDEKE, M., JANECEK, A. and KOHLMAIER, G. H. 1991. Modelling the seasonal $\mathrm{CO}_{2}$ uptake by land vegetation using the global vegetation index. Tellus, 43B: 188-196.

MCGAUGHEY, R. 2018. FUSION/LDV: software for LiDAR data analysis and visualization, version 3.70. USDA Forest Service, Pacific Northwest Research Station, University of Washington, Seattle, Washington, USA.

MENCUCCINI, M. and GRACE, J. 1995. Climate influences the leaf area/sapwood area ratio in Scots pine. Tree Physiology, 15(1): 1-10.

MIKITA, T., PATOČKA, Z. and SABOL, J. 2014. Estimation of leaf area index (LAI) in forests on the basis of airborne laser scanning in the conditions of the Czech Republic [in Czech: Výpočet indexu listové plochy (LAI) v lesních porostech na základě dat leteckého laserového skenování v podmínkách České republiky]. Reports of Forestry Research, 59(4): 234-242.

MONSI, M. and SAEKI, T. 2005. On the factomonsir light in plant communities and its importance for matter production. Annals of Botany, 95(3): 549-567. 
MORRISON, I. K. 1991. Effect of trap dimensions on mass of litterfall collected in an Acer saccharum stand in northern Ontario. Canadian Journal of Forest Research, 21(6): 939-941.

MUSSCHE, S., SAMSON, R., NACHTERGALE, L. et al. 2001. Acomparison of optical and direct methods for monitoring the seasonal dynamics of leaf area index in deciduous forests. Silva Fennica, 35(4): 373-384.

MUSSELMAN, K. N., MARGULIS, S. A. and NOAH, P. M. 2013. Estimation of solar direct beam transmittance of conifer canopies from airborne LiDAR. Remote Sensing of Environment, 136: 402-415.

MYNENI, R. B., NEMANI, R. R. and RUNNING, S. W. 1997. Estimation of global leaf area index and absorbed par using radiative transfer models. IEEE Transactions on geoscience and remote sensing, 35(6): 1380-1393.

PEDUZZI, A., WYNNE, R. H., THOMAS, V. A. et al. 2012. Combined use of airborne lidar and DBInSAR data to estimate LAI in temperate mixed forests. Remote Sensing, 4(6): 1758-1780.

PIROTTI, F. 2011. Analysis of full-waveform LiDAR data for forestry applications: a review of investigations and methods. iForest, 4(3): 100-106.

QU, Y., SHAKER, A., SILVA, C. A., KLAUBERG, C. et al. 2018. Remote Sensing of Leaf Area Index from LiDAR Height Percentile Metrics and Comparison with MODIS Product in a Selectively Logged Tropical Forest Area in Eastern Amazonia. Remote Sensing, 10(6): 970.

RIAÑO, D., VALLADARES, F., CONDÉS, S. and CHUEVICO, E. 2004. Estimation of leaf area index and covered ground from airborne laser scanner (Lidar) in two contrasting forests. Agricultural and Forest Meteorology, 124(3-4): 269-275.

SOLBERG, S. 2010. Mapping gap fraction, LAI and defoliation using various ALS penetration variables. International Journal of Remote Sensing, 31(5): 1227-1244.

ZHENG, G. and MOSKAL, L. M. 2009. Retrieving Leaf Area Index (LAI) Using Remote Sensing: Theories, Methods and Sensors. Sensors, 9(4): 2719-2745.

Contact information

Zdeněk Patočka: zdenek.patocka@mendelu.cz 